\title{
LA ÉTICA Y SU INFLUENCIA EN LA GESTIÓN INSTITUCIONAL DE ENTIDADES EDUCATIVAS PRIVADAS DE ENSEÑANZA SUPERIOR
}

José D. Begazo Villanueva*

d180045@mixmail.com

\begin{abstract}
RESUMEN
Las instituciones educativas tienen significativas funciones sociales y culturales en la construcción de la sociedad y con respecto a los importantes cambios que se están produciendo en el mundo, sobre todo cuando buscan modos diversos de disminuir la inequitativa distribución de la riqueza, promover la movilidad social y estudiar y formular opciones de solución para problemas prioritarios. Los valores y el comportamiento ético son parte de estos asuntos.

Las profesiones y los profesionales de todas las áreas del conocimiento ocupan un lugar significativo en el mundo social, pues aportan bienes y servicios que requiere la propia sociedad. Su desempeño y actuación están siempre en la mira de los sectores, grupos e individuos (a nivel local, regional, nacional e internacional). El comportamiento ético es parte intrínseca de la profesión y del sentido y proyectos de vida de los sujetos. Constituye, además, junto con la competencia profesional y técnica, lo que las personas mejor pueden apreciar de su labor.

Hoy se vive una especial sensibilidad y demanda social de ética con respecto a los profesionales. Se insiste con mayor frecuencia en la importancia de incorporar elementos éticos en su formación y en el ámbito de investigación científica y sociocultural. Paulatinamente, se han ido introduciendo asignaturas de ética y deontología profesional (9) en las titulaciones universitarias y en las instituciones de educación superior. En los países de Europa Occidental y en los Estados Unidos de América y Canadá se han multiplicado los comités de ética, principalmente en los ámbitos de la ciencia. Han aparecido recientemente en sectores muy diversos, como son: universidades, empresas, ministerios y organismos, a escala nacional e internacional.

La ética profesional es un campo interdisciplinario que puede contribuir a aminorar el aislamiento en que se encuentran las especialidades, para integrarlas en una perspectiva de conjunto. La ética compete a todas las profesiones, no solo a cada una de ellas, sino también a los campos de interacción que se producen para resolver problemas sociales complejos.
\end{abstract}

Palabras clave: Código ético, colaboración compromiso, eficiencia, eficacia, ética, justicia.

* Doctor en Administración, Licenciado en administración de empresas cooperativas, Docente principal de la UNMSM, Decano de la Facultad de Ciencias Administrativas. 


\begin{abstract}
Educational institutions have significant social and cultural functions in the construction of society and with respect to the major changes taking place in the world, especially when looking for different ways to reduce the inequitable distribution of wealth, promote social mobility and study and formulate options for solving priority problems. The values and ethical behavior are part of these issues.

The professions and professionals from all areas of knowledge, occupy a significant place in the social world, as they provide goods and services required by society itself. Its performance and performance are always on the look of the sectors, groups and individuals (local, regional, national and international). Ethical behavior is an intrinsic part of the profession and the meaning of life and projects of subjects. It is also, along with the professional and technical competence, so that people can better appreciate your work. Today there is a special sensitivity to ethical and social demands regarding professionals.

It most often insists on the importance of incorporating ethical elements in their training and in the field of scientific research and socio - cultural. Have been introduced gradually subjects of ethics and professional conduct (9) in university degrees and higher education institutions and the countries of Western Europe and the United States of America and Canada have increased ethics committees, primarily in the fields of science. Have appeared recently in very diverse sectors, such as: universities, ministries and agencies, national and international.

Professional ethics is an interdisciplinary field, which can help reduce the isolation that are the specialties, to integrate them into an overall perspective. The ethical responsibility of all professions, not just to each of them, but also to the fields of interaction that occur to solve complex social problems.
\end{abstract}

Keywords: Code of Ethics, Commitment Collaboration, Efficiency, Effectiveness, Ethics, Justice.

\section{INTRODUCCIÓN}

Actualmente el país y todas las estructuras que lo sustentan se encuentran sumergidos en una crisis que está planteada en todo nivel: económico, político, educativo (sector al cual se le endosa una alta cuota de responsabilidad), religioso, militar, gremial e incluso de orden moral.

Diversos estudiosos plantean que la solución a esta diversidad de crisis se puede abordar fundamentalmente desde un punto de vista educativo.

Las actividades humanas de mayor envergadura giran en torno a los grandes valores, y las ciencias buscan también algunos valores.

El profesional de la docencia no puede esquivar o eludir su responsabilidad ante una sociedad en plena transformación. Hay una responsabilidad directa en la gestión de los asuntos públicos que debe complementarse con un código de ética de obligada observancia, dado que toda amenaza al mismo es una amenaza al espíritu de la organización y, en particular, a la organización educativa donde se desenvuelve profesionalmente.

En una sociedad en donde la crisis de valores es reseñada y apuntalada casi a diario, las prácticas antiéticas en contra de la organización son modos seguros de agravar las desigualdades y la marginación social. Los códigos de ética se pueden presentar como elementos de equidad, que se reflejarán en la organización social, la competitividad, la transparencia y la excelencia en el desempeño de funciones y prestación de servicios (como el educativo, por ejemplo).

\section{MARCO TEÓRICO}

\section{ANTECEDENTES HISTÓRICOS}

Las instituciones educativas de nivel superior han sido, desde sus orígenes, las encargadas de formar profesionales y especialistas en las diversas áreas del conocimiento. Además de realizar esta importante tarea, han contribuido decididamente en la formación de los ciudadanos.

Por ello, conocimiento ha sido siempre la base de conformación de las profesiones. La complejidad creciente del conocimiento, las técnicas avanzadas y habilidades especializadas, así como los problemas vinculados a su puesta en práctica, han generado mayor atención con respecto a la ética profesional.

La ética profesional es un campo interdisciplinario que puede contribuir a aminorar el aislamiento en que se encuentran las especialidades, 
para integrarlas en una perspectiva de conjunto. La ética compete a todas las profesiones, pero no solo a cada una de ellas sino también a los campos de interacción que se producen para resolver problemas sociales complejos.

Asimismo, ayuda a reflexionar sobre qué debe hacer un buen profesional para serlo. Para cada una de las profesiones, es significativo: clarificar los bienes y servicios que brindan a la sociedad, sus beneficiarios directos e indirectos, los modos más apropiados de ofrecer dichos bienes y servicios, la complejidad del trabajo profesional en las diversas organizaciones públicas y privadas, la posibilidad de que se produzcan conflictos éticos durante el ejercicio profesional, la problemática de identidad profesional cuando los estudios no coinciden con las ofertas de empleo, la existencia y vigencia de asociaciones, colegios profesionales y códigos y la oportunidad de contribuir -a través de la profesión- al mejoramiento de la sociedad. Estos conocimientos e información son de gran utilidad para los profesionales en ejercicio y para los profesores y estudiantes universitarios.

En este campo de investigación, es relevante formular la pregunta acerca de los principios y valores prioritarios que conforman la ética profesional en las distintas áreas de conocimiento de las instituciones de educación superior. Especialmente importante es indagar si los alumnos los conocen y comparten y cómo piensan que pueden utilizarse en la práctica profesional. Complementariamente, saber si existen códigos éticos de la profesión y si los estudiantes universitarios pueden identificarse con ellos.

\section{BASES TEÓRICAS}

El marco teórico se fue construyendo paulatinamente con informes investigación, bibliografía, hemerografía, documentos, principalmente de autores de Colombia y Argentina. También se analizaron algunos trabajos de investigadores de México y España.

La obtención de a la información fue directa en el tema de ética profesional y ética de las instituciones e indirecta, sobre: valores específicos, principalmente responsabilidad ética profesional como parte de las éticas aplicadas; sociología de las instituciones educativas de nivel superior, específicamente sobre ideología del profesionalismo e identidad profesional, ética de las ciencias y de la investigación científica, ética de la docencia y ética de la educación.
Consta de los siguientes aspectos: investigaciones relevantes del estado del conocimiento elaborado en Perú sobre valores de instituciones educativas de nivel superior y profesionales y especialmente sobre ética profesional, ética profesional como parte de las éticas aplicadas; antecedentes, definiciones y caracterización de la profesión en general y de la ética profesional en particular, diferencia entre ética y deontología, principios de la ética profesional, influencias económicas, técnicas y organizacionales en el ejercicio profesional; valores fundamentales como son competencia profesional y responsabilidad, identidad profesional, ética de la docencia, ética de las ciencias y de la investigación científica y propuestas de formación de valores en este campo.

\section{MÉTODOS Y RESULTADOS}

El trabajo de campo inicial fue de tipo exploratorio; simultáneamente se hicieron estudios de casos muy concretos permitiéndonos identificar las instituciones que están aplicando la ética en todos sus actos y acciones de gestión educativa para obtener no solo una mejor competitividad sino, sobre todo ser un ejemplo ante la sociedad de su accionar como institución de formación de profesionales, obteniendo además un clima e integración laboral entre sus colaboradores.

Para tal efecto, a fin de medir las acciones y comportamientos éticos, se utilizaron técnicas cuantitativas como encuestas y entrevistas a sus líderes o directores de las instituciones educativas, así mismo, se utilizaron técnicas cualitativas como investigación documental y guías de observación.

\section{ANÁLISIS Y DISCUSIÓN}

La ética profesional genera, en su propio ámbito, una clasificación de situaciones, asuntos, conflictos y modos de abordarlos y resolverlos, que permiten analizar lo que está en juego en la toma de decisiones.

Los principios son imperativos de tipo general, que orientan acerca de lo que es bueno hacer y lo que debe evitarse. Se distinguen de las normas por ser más genéricos. Señalan grandes temas $\mathrm{y}$ valores de referencia, que hay que tomar en cuenta a la hora de decidir y de enfrentar casos problemáticos. Las normas aplican los principios a situaciones más o menos concretas.

Los principios pueden ser el punto de partida o de llegada de una actuación. El "razonamiento 
moral descendente" va de los principios generales a otros más específicos, paulatinamente, hasta llegar a las decisiones singulares. Para ser aplicados, deben ser revisados e interpretados con respecto al contexto en que se producen y a las situaciones y casos que se busca resolver. El "razonamiento moral ascendente" parte de las actuaciones y decisiones singulares en situaciones concretas. De ahí se van generando criterios de actuación, hasta llegar al nivel más general de los principios. Ambos procesos se combinan.

En la ética profesional están implícitos al menos tres principios:

\section{Beneficio o beneficencia}

"La palabra beneficencia está compuesta de dos vocablos de origen latino, bene y facere, que podrían traducirse como hacer el bien. Hace referencia a la consecución de determinados bienes específicos de la práctica profesional correspondiente".

Cada profesión se legitima frente a los demás en la consecución de ciertos bienes y servicios. Para ser buenos profesionales, los individuos deben conocerlos y buscar su cumplimiento, tanto con respecto a los usuarios que reclaman un trabajo bien hecho, como de la sociedad en su conjunto, que pretende resolver problemas prioritarios con la contribución de los profesionales.

Detrás del secreto profesional (y de las patentes) se oculta, muchas veces, la apropiación y el monopolio sobre una parcela del conocimiento, que de ser manejada bajo principios éticos, ayudaría a resolver importantes problemas sociales.

\section{La autonomía}

Procede del griego: autos (sí mismo) y nomos (ley) y hace referencia a la capacidad que tiene cada cual de darse a sí mismo sus propias normas, procurando construir la propia vida a partir de ellas" (Bermejo, 2002,105).

En este segundo principio hay dos acepciones. Una de ellas se centra en el profesional que requiere independencia y libertad para poder realizar adecuada y éticamente su trabajo, y la otra se centra en el beneficiario que posee derechos que deben ser respetados.

\section{La justicia}

La ética profesional queda incompleta si no se enmarca en la perspectiva de una ética social, que permita entender en qué contribuye o puede contribuir el trabajo de cada profesión a mejorar la sociedad. Los profesionales son las personas y grupos más competentes y mejor ubicados socialmente para promover una distribución más racional y justa de los recursos, que son siempre escasos y que se requieren para conseguir múltiples y variados fines. Las preguntas básicas son: ¿qué es lo justo? y ¿qué es prioritario cuando no hay recursos para satisfacer las demandas de todos?

Un buen profesional tiene, o debería tener, siempre presente el contexto social de referencia y las obligaciones de justicia. La ética profesional permite reflexionar sobre si la función social que desempeña una profesión es la misma que la que la sociedad necesita de ella.

Con el principio de justicia, se hacen presentes tres protagonistas:

a) Los usuarios que reclaman determinados bienes y servicios.

b) El profesional que requiere de medios para ofrecerlos.

c) Los responsables públicos, que representan al conjunto de la sociedad y buscan conseguir un cierto equilibrio entre las necesidades, exigencias y expectativas de todos.

Es importante que los clientes y usuarios sean conscientes de que también dependen de la capacidad de las instituciones de responder a sus demandas y de su propia adaptabilidad a lo que estas pueden proporcionar.

\section{CONCLUSIONES}

1. La práctica de los valores éticos, como parte de la cultura y gestión de las instituciones de educación de nivel superior, constituye uno de los principales activos de las organizaciones, por cuanto genera confianza y transmite una buena imagen a los que con ella se relacionan. Instituciones educativas duraderas son aquellas cuyos trabajadores manifiestan comportamientos éticos en el logro de sus objetivos, lo cual los lleva a la eficacia institucional educativa.

2. Los resultados revelan que las instituciones educativas que tienen comportamientos antiéticos tales como: robos, mensajes publicitarios deshonestos, difamación, etc, así como omisión de valores éticos están originando el caos institucional y, por ende, no logran ser eficaces. 
3. Una institución educativa de nivel superior será eficaz consigo misma y su comunidad a la que sirve, siempre y cuando sus trabajadores practiquen valores éticos, los cuales beneficiarán a ellos mismos y a la institución por cuanto logran ser aceptados por su comunidad, además de ser eficaces y eficientes en lo que realizan.

\section{LITERATURA CITADA}

Ávila, Roberto (1995) Introducción a la Metodología de la Investigación, Lima Ediciones RA 148 pág.

Donnelly, James (1997) Fundamentos de la dirección y Administración de Empresas, Colombia. Edit. McGraw-Hill 848 pág.

Fernández, José (1996) Ética para empresarios y directivos. Madrid Edit. ESIC 238 pág.

Freemont, Kast (1992) Administración en las organizaciones. México Edit. McGraw-Hill 742 pág.
García, José (1991) Identificación del valor justicia en estudiantes de educación de Lima. Tesis para optar el título de licenciado en educación, Facultad de Educación UNFV.

García, Rafael (1990) Ética empresarial: teoría y casos. España Edit. RIALP S.A. 166 pág.

Hernández, Roberto y Fernández, Carlos (1997) Metodología de la Investigación. México Edit. Mc Graw. 505. pag.

Ortega, Maritza (1989) Estudio de las relaciones entre las dimensiones de la personalidad y la elección de valores interpersonales. Tesis para optar el título de Licenciado en Psicología. Facultad de Psicología de la UNFV.

Regal, Bernardo (1988) Fundamentos de ética profesional. Lima Edit. U. de Lima. 208 pág.

Schmidt, Eduardo (1995) Ética y negocios para América Latina. Lima Perú Edit. OXY 603 pág. 